\title{
On learning from the patient: hearing voices
}

\author{
Ann Warnes, Geraldine Strathdee and Kamaldeep Bhui
}

\begin{abstract}
This paper presents the coping strategles developed by one patient with 18 years experience of managing her own schizophrenic illness. The interventions which evolved gave her significant control over her illiness. We report her experiences and emphasise that for some patients with treatment resistant schizophrenia, the patients themselves may have expertise in managing their symptoms.
\end{abstract}

Pharmacological advances in the treatment of positive symptoms of schizophrenia remain unsuccessful for a significant proportion of patients. Up to $60 \%$ of patients continue to have delusions and $23 \%$ report florid symptoms which are disabling and a distressing component of their lives (Garety et al, 1994). Even clozapine is effective in only a third of patients who theoretically would benefit (Kingdon, 1994). Psychological approaches such as social reinforcement, time out, punishment, assertiveness training, stimulus control, self-instruction, belief modification, thought stopping, biofeedback and self-control (Tarrier et al, 1993) have been demonstrated to be effective in uncontrolled case studies. Some individuals who hear voices are helped by wearing an earplug, listening to music or watching television (Margo et al, 1981). Patients appear to suffer more from the lack of control over hallucinations than from their existence alone (Romme \& Esher, 1989). The remarkable similarity of described strategies in clinically different populations in the absence of prescribed interventions suggests that these have evolved by trial and error and may be the basis of further novel interventions (Falloon \& Talbot, 1981). Such interventions could then give rise to more widespread clinical application and better symptom control with fewer adverse effects than pharmacological approaches.

Psychiatric assessments continue to focus on the systematic description of clinical symptoms, yet there is little attention directed at routinely eliciting the individual's own painfully developed coping strategies. The evidence suggests that with all treatment packages, over-prescribing is frequent and the use of alternative strategies is uncommon in patients with schizophrenia (Holloway, 1989). This article presents the range of coping strategies developed by one patient during 18 years of managing her psychiatric symptoms (AW).

\section{Description}

AW developed schizophrenia at the age of 24 years in 1975. Auditory hallucinations and thought broadcasting have been the predominant symptoms, and have been persistent throughout the illness except for two one-year periods in 1976-1977 and again in 1986-1987. AW has had four episodes of a more severe and acute nature, but has only had one hospital admission. At an early stage in her illness, she felt that it was important for her not to allow the illness to 'take over' her life and decided that she would consciously work to develop strategies to minimise the impact of her symptoms. The strategies, painstakingly developed over the past 18 years while pursuing an active full-time working and social life, are presented as if giving advice to a fellow sufferer.

\section{Coping with voices}

1. When you have voices, the thoughts which come into your head are probably what you find most frightening and make you feel guilty. If you can release these in some way, you are half way there. This will relieve the tension and the stress.

2. The most important thing is to try and physically relax when the voices are at their worst.

3. If you can remember when you were free of the voices, return to that time and think about it. This will help counteract the voices.

4. Try and think of a way out of the dilemma the voices are putting you in. Try an argument in your head with which the voices cannot argue.

5. Busy yourself doing things which you can do automatically; do not try anything which requires concentration as this will only frustrate you.

6. Crying can help. Make yourself cry until you can cry no more. This in itself will help relieve stress. 
7. Chatter back at the voices; it will make sense to you and your voices but not to the people around you. This tactic is best used when noone else is present.

\section{Coping with company}

1. If you are in company when the voices are trying to get you to say or do something, relax physically and concentrate on relating to the real people around you. Do not talk about what you are feeling, but try and talk about what the other people want to discuss. If in difficulty, ask them to repeat what they are saying. Concentrate on them, not on your voices.

2. Try to concentrate your mind on the physical reality around you, rather than the mental reality. You will mostly find that the reality of the people around you is more secure than the voices in your head. This is hard to believe, but it is a fact.

3. If you hear voices talking about you in a different room, you will probably find the conversation will change as you enter the room; do not challenge the occupants of that room; the voices are inside your own head. The conversation you heard as you entered the room was the reality.

4. Remember the people around you cannot hear your voices, and these people will have more of a grasp of reality. This will help you realise that your voices, although very real, are not the actual reality.

\section{Talking about voices}

1. If you want to talk about them, try a sympathetic listener. Avoid talking to those who think such 'happenings' are a joke.

2. Try not to monopolise your sympathetic listener if he or she is a layman; if you do, their compassion can wear a bit thin.

3. Screaming and shouting will only distress listeners. Try to be patient and retain your self-control.

4. Someone just holding your hand can make all the difference.

5. Getting drunk will not help, as you become physically less capable of standing up to the voices and probably depressed as well.

\section{Thinting away from the voices}

1. Playing music, often very loud, helps.

2. Watch a frightening thriller on television. Even if you would normally find this frightening, you can concentrate on it because it is a different fear to the voices and so better.

3. Writing and reading are difficult with the voices, but having to explain or concentrate on a difficult task overcomes them if you have to focus on one particular person or issue. If you let your concentration go, or get distracted, the voices take over.

4. If you go for a walk or take exercise, you will cheer up, even if the voices are still present.

5. Plan interesting, absorbing and pleasurable events at regular intervals in your working and leisure life. Having targets to reach helps you have a sense of achievement and makes you realise that the voices are only a part of your life, not all of it.

\section{General advice}

1. You are not that important; not many people would be continually talking about you.

2. Often, what you hear the voices say will correspond to the same number of syllables in a word or phrase of another totally independent conversation. Your mind will have interpreted that conversation as something frightening or horrible, only known to you.

3. You may hear the odd word or two from another conversation and take it out of context into whatever is bothering you inside your head, rather than the reality of that other conversation.

4. If you cannot sleep at night, just lie in bed. You will find you have rested, even if you do not appear to sleep. Often, the passage of time will ease the fright or nastiness of the day before, and the next day something new may be bothering you.

\section{My advice}

1. If you can retain your self-control, be patient and relax physically, you will not need so many tranquillisers and will not end up feeling like a 'zombie', and most other people will not know you are on any drugs at all.

2. Once you have lost the voices, do not do nothing. You need the stimulus of other people. Mix with them. Join an activity outside the hospital.

3. At first you will not have anything to say so listen to what the others talk about. Eventually you will be able to join in and talk about what activity you are doing and what other people have told you.

\section{Discussion}

GS is a consultant community psychiatrist, working with PACT (Psychiatric Assertive Outreach and Continuing Care Team), in South London. She regards AW's approach as having been a significant influence on her clinical training and practice over a 13-year period. The coping mechanisms developed above have 
painstakingly evolved in the 18 years in which $\mathrm{AW}$ has persisted in trying to lead a normal life, in spite of her illness. The level of sophistication of the strategies and their practicality is striking, but few of the management strategles described above are contained as items in the currently available standard assessment rating scales; yet they have been among the most powerful techniques which the PACT team have been able to impart to their patients. The growth of successful behavioural-cognitive treatment is much welcomed (Garety et al, 1994) but even though such techniques are now more universally accepted, perhaps we as mental health professionals best discover creative, individually tailored approaches to persistent psychotic symptoms by listening to, and working with, our patients and their unique evaluations of their symptoms.

\section{References}

FALLON, I. \& TALBOT, R. (1981) Persistent auditory hallucinations: coping mechanisms and implications for management. Psychological Medictne, 11, 329-339.

GARETY, P., KUIPERS, L., et al (1994) Cognittve behaviour therapy for drug resistant psychosis. British Joumal of Medical Psychology, 67, 259-271.
Hounoway, F. (1988) Prescribing for the long-term mentally ill. A study of treatment practices. Brttish Journal of Psychiatry. 102, 511-515.

KINGDON, F. (1994) Cognittve behaviour therapy of schizophrenia. British Journal of Psychiatry, 164, 581.

MARGo. A. Hemsley, D. \& SLADE, P. (1981) The effects of varying auditory input on schizophrenic hallucinations. Brttish Medical Journal, 189, 122-127.

ROMME, M. \& EsCHER, A. (1989) Hearing volces. Schizophrenia Bulletin, 18, 209-217.

RICE, K. \& DONNELY, P. (1991) The use of rating scales by consultant psychiatrists. Psychiatric Bulletin. 16. 114.

TARRIER, N., BECKETT, R., HARWOOD, S., et al (1993) A trial of two cognittve-behavioural methods of treating drugresistant residual psychotic symptoms in schizophrenic patients: 1. Outcome. Brttish Journal of Psychiatry. 162. 524-532.

Ann Warnes, Mental Health Service User, *Geraldine Strathdee, Consultant Community Psychiatrist, Maudsley Hospital; and Kamaldeep Bhui, Senior Registrar, Maudsley Hospital, Denmark Hill, London SE5 8AF

-Correspondence: Dr G. Strathdee, Head of Service Development. Sainsbury Centre for Mental Health. 134-138 Borough High Street, London SE1 1LB 